\title{
LA RECUPERACIÓN DE LA MANSEDUM- BRE: ALREDEDOR DEL ESPÍRITU Y LA OBRA DE SAN JUAN BOSCO
}

Monseñor Luis Alberto Luna Tobar (Arzobispo Emérito de la ciudad de Cuenca)

Discurso de Incorporación como "Doctor Honoris Causa", otorgado por la Universidad Politécnica Salesiana del Ecuador.

$\mathrm{D}$ on Bosco, al acogerme al mundo universitario de su espíritu y de su obra, me exige que me "enloquezca un poco", promoviendo la recuperación de la mansedumbre en la Universidad, como uno de los objetivos sociales más requeridos por el mundo presente y la cultura ambiente, poseídos por la violencia.

Presumo de haber profundizado, desde hace muchos años, en los sueños de Don Bosco y de haber llegado, como pueden haber convenido muchos lectores estudiosos, a admitir que el sueño fue en él un modo profético de Providencia, muy acorde con la alegría y la generosidad propias de la personalidad del Santo: las virtudes adecuadas para el que debía ser un innovador fundamental en la pastoral de las juventudes y en la misma línea universal del compromiso de la Iglesia con el mundo presente y sobre todo con el laico en el ambiente actual.

Todo ser humano nace para su siglo, para su tiempo. Casos extraños nacieron mucho después de su época y quedaron anclados en la edad media y tal vez en el patriarcado de la Antigua Ley; pero algunos seres excepcionales nacieron para mantener su vigencia más allá de su tiempo y ese poder aborigen les concede el don de entender su propio tiempo, de rescatar constantemente la tradición heredada y de acumular en su contorno social una predisposición, realmente profética, de humanismo comprensivo y de autenticidad liberadora. Ese es el caso de la personalidad y de la obra de Don Bosco.

Su visión de laicado en la doctrina de la Iglesia, presente en el mundo, es la del Vaticano II; su línea pedagógica coincide con lo fundamental de las teorías personificadoras con una fuerza asociadora y comunitaria que demuestra la visión presente del mejor 
magisterio pedagógico. Pero, casi en evidente contraste y contraposición con posiciones derivadas de la pasión por el mercado, que hoy nos caracteriza, la entrega de Juan Bosco a los jóvenes se basaría en la conquista del mundo por la mansedumbre, no por la dominadora violencia de los sistemas y de las prácticas de los que hoy es objetivo y víctima la juventud.

La doctrina espiritual que Don Bosco ha conformado con su vida y sus cartas o escritos y con su ejercicio del magisterio de lo sobrenatural y humano que corresponde a todo ser superior comunitario y mucho más a un fundador, son revelaciones de la gran "oportunidad" de Dios, de esa contemporaneidad permanente que los seres endiosados poseen como gracia y la entregan y mantienen entre los suyos como carisma. He dicho, "entre los suyos"y debería detenerme un instante para formular una pregunta: ¿quién no es suyo y quiénes son los suyos?...

Un análisis muy comprometido de esta espiritualidad permite recordar mientras se lo realiza y se llega a formular contenidos doctrinales básicos, aquello que todos los contemporáneos del Santo y sus posteriores biógrafos, declaran en total acuerdo: lo fundamental en su personalidad fue la mansedumbre.

La asumió de su maestro espiritual, Francisco de Sales. En ella se condensan y desde ella brotan todas las peculiaridades definidoras de los salesianos. El origen de su nombre determina también la categoría fundamental de su personalidad comunitaria e individual. Creo no estar equivocado y creo tener un argumento válido para proponer, en momento tan importante para mí, la recuperación de lo manso, desde todo lo salesiano, que en el mundo es imponderable y que en estos centros de formación universitaria es básico y exigente. La violencia que nos circunda, también apoya todo recurso a esa virtud generadora de paz y con ella de verdadero desarrollo humano.

En las Memorias del Oratorio de San Francisco de Sales señala Don Bosco el fundamento de su decisión pedagógica y ascética por la mansedumbre. Será de profundo interés conocer el mundo de violencias que viviera este hombre providencial y contrastarlo con las de nuestra era, para descubrir el significado demoledor que ellas tuvieron siempre y la importancia fundamental de lo manso -que hoy llamaremos no violencia activa- como nor- 
ma de vida y formación personal y comunitaria. En esas Memorias recoge Juan Bosco unas palabras soñadas, que indiscutiblemente son de Cristo. De frente a la preocupación del Santo por la juventud torinense, cargada de odio, blasfemias y violencia destructora, Jesús le dice: "No con golpes, sino con mansedumbre tienes que ganarte su amistad... Yo te daré la Maestra que te instruya, para que tú te hagas sabio". Y esa Maestra - que es María Auxiliadorale dice: "Sé humilde, fuerte y robusto y ellos cambiarán".

Cambiaban, el sueño se traducía en conducta.

La mansedumbre, unida a la humildad, a la fortaleza y robustez, fijan la actitud pedagógica y ascética de los salesianos; pero estos valores se entienden de modo singular, en la perspectiva de cada tiempo. En el instante de la fundación de los Oratorios y en el inmediato de la comunidad salesiana, cunden en el mundo cambios fundamentales en la actitud y cultura universal, con implicaciones terminantes en la historia social. Produce un profundo gozo admirador la respuesta que a esos cambios da Juan Bosco en la formación de los jóvenes más necesitados y violentados por el mundo del instante y en la preparación de sus hijos salesianos para afrontar con él la misión que la Providencia les daba para un mundo enloquecido y para un tiempo más necesitado de esperanza, como el nuestro.

Cuando se forma el primer oratorio, con jóvenes sin conexión social alguna, ya el mundo desconocía los argumentos de antigüedad, consanguinidad y homogeneidad sensible que fundamentaban, en otras horas, una suerte de solidaridad racial y local, sin mayor comunión, pero con un poder relativo de integración. La ciudad comenzaba a ser despersonalizadora y ciertas primerizas integraciones generaban grupos de seres que nunca se conocieron, más aún, que se desconocían de principio.

La unión entre desconocidos abortaba hombres - soledades, incapaces de compartir y muy capaces de destruir. Esos son los primeros problemas y luchas del Oratorio: desarmar a los jóvenes. Desarmados de toda violencia, hija del resentimiento social generado por la injusticia del ambiente, se tenía que incentivar el corazón, aún no amortiguado y entumecido de los jóvenes sin familia, sin medio social, sin estímulo gregario de barrio, para que comprendieran lo que significa "compartir". Juan Bosco es un cris- 
tiano de Emaús y su madre le educó en el darse y recibir, en el comprometerse y conseguir el aporte del más lejano.

Maestro en el arte de compartir, que lo mismo importaba contar un sueño que dar pan y techo, que enseñar un juego, que asistir enfermos, levantar y perdonar caídos o raterillos, que acompañarán al que se perdió de la casa o se olvidó de su contorno, debía descubrir e implantar un nuevo sentido de comunidad y un arte exquisito de comunión.

Mago, titiritero, entretenedor capaz de hacerle sonreír a Dios, llegó al magisterio del compartir afirmando que esa actitud cultural humana no es fruto de la geografía, de la etnografía, de la tradición, de la riqueza o la pobreza, de los grandes estudios o de la simplicidad primeriza. El compartir exige valores nuevos.

$Y$ aquella mujer que instituyó, en la Iglesia, la norma pastoral que ha perdurado siglos, cuando consiguió adelantar las horas de la oportunidad de Dios en Caná, para que el amor de los pobres fuera fiesta celebrada con el mejor vino, le dijo a Juan Bosco unas palabras conocidas que Ella acaso las presintió en algún sueño, como los de nuestro santo: "Haz lo que mi Hijo diga". Y Cristo le dice, repetidas veces, algo que se siente en los sueños de Don Bosco: "La solidaridad, tan solo se alcanza y vive desde nuevos valores". "Juan, descubre un mundo nuevo", "Juan eres el Bautista de un cristianismo diferente" surgen nuevas formas de comunidad, con nuevos valores y en otras dimensiones de las conocidas y de las ya demasiado desgastadas.

En el primer sueño de Don Bosco aparecen cuatro términos excepcionales que son categorías de gracia y de humanidad: "mansedumbre" que la pide Jesús para el trato de los niños en el primer Oratorio Festivo y "humildad", fortaleza y robustez, que considera María elementos propios de la praxis pedagógica nueva.

Grandes exegetas, a los que envidió de todo corazón, se entretienen en examinar estos valores en el contexto de lo soñado que, de partida, para todo experto en la vida espiritual, no son sueños: son aquellos que el mayor místico de la Iglesia llama "los levantes de la aurora", esos claroscuros de amanecida en los que los contemplativos descubren el rostro, la voz y la voluntad de Dios, previstas, "aunque es de noche" en fe de tenue luz, pero se asegura esperanza y amor verídico. Es Dios mismo el que hace 
soñar a Juan Bosco como si aún fuera niño, en ese mismo estilo en el que Juan hace dormir y soñar a tantos niños que, por primera vez en sus vidas, durmieron sin hambre y en una cama limpia.

La mansedumbre -en cuanto sustantivo- es desconocida en la antigüedad.

Las palabras "prais kai tapeinos" -adjetivos manso y humilde- son del griego no bíblico; la primera cuenta significados contradictorios entre sí y con los presentes. Para Jenofonte es la dulzura vegetal y animal; para los aristotélicos revela la endurecida sensibilidad espartana; Platón sueña en su República que los gobernantes sean tan dulces con sus áulicos como duros con sus enemigos. En el Antigüo Testamento, el prais -manso- se emparenta con términos hebreos que significa humildad y miseria: "ani, amawah". Isaías y Sofonías preludian el sentido evangélico de la tercera bienaventuranza que Jesús llamó "manso y humilde de corazón" que es una de las primeras novedades de la Buena Nueva. Es San Pablo quien mejor nos guía hacia el entendimiento preciso que Jesús tuviera de su propia mansedumbre: "Así sean los que sufren, como si no sufrieran, los que gozan, como si no gozaran, los que adquieren, como si no poseyeran": manso desprendimiento imperturbable, cuajado de ternura comprometida.

Dice la tercera bienaventuranza: "Dichosos los mansos, porque ellos poseerán la tierra", mientras la poseen, los expertos bíblicos optan por tres diferentes interpretaciones del manso evangélico. La primera, de tipo sociológico, pretende que consideremos mansos a los infelices oprimidos, abusados y humillados, cuya bienaventuranza es exclusiva dependencia divina.

Están sujetos a un Dios que los ama y así hay que creerlo...

La segunda interpretación es espiritualista y considera la mansedumbre como revelación de la serenidad interior, de la paz cordial, del equilibrio mental y de la dulcedumbre de la paz cordial, del equilibrio mental y de la dulcedumbre en las actitudes, derivadas de una fe y confianza en el Señor que, como la afirma Isaías y lo acoge el Salmista, conceden la seguridad de poseer todo lo esperado en la comunidad de hijos herederos.

La tercera interpretación, considerada ambivalente o mixta, afirma que la mansedumbre es equivalente de la resignación pasi- 
va y silenciosa. La mayoría cristiana está por la segunda tesis, espiritualista y allí consta, en su radical espiritualismo, jamás privado de encarnación y terrenalidad, el valor esencial de la mansedumbre en la vida comunitaria, que es el inicio fundamental del Reino, en el que, por obra de la no violencia activa, conquistamos la paz y presentimos la definitiva bienaventuranza.

Cómo consigue Juan Bosco, desde su indiscutida y notoria mansedumbre, esa no violencia activa de la alegría salesiana, con la que ha conquistado el mundo en sus Oratorios Festivos, en sus colegios técnicos, en la definición nueva de sus colaboradores -ensayo de participación del seglar en el compromiso pastoral de una Iglesia postvaticana-, en la catequesis misionera del universo, asumida como carisma especial de una familia y en todo lo que el salesiano, a partir de su secular historia es y significa. Una pregunta para todos los expertos en consultarle al mundo sobre sus valores, a la historia sobre sus logros y a la fe sobre su presencia redentora.

Es el instante en el que, acogiendo el consejo maternal de María Auxiliadora y como si volviéramos a sentir la noble inducción materna de mamá Margarita, oyéramos todos unas palabras que son técnica conductora para llegar desde la mansedumbre al cambio que el mundo necesita y que, sobre todo la juventud, la busca y espera de lo salesiano: "con humildad, fortaleza y robustez" fueron las palabras oídas de labios de la madre por Don Bosco.

Es la alegría el hilo conductor entre la mansedumbre personal y la serenidad y estabilidad comunitaria, que la busca Juan Bosco para su jóvenes del Oratorio y para sus hermanos, hermanas y colaboradores de la obra salesiana. En esa alegría, expresión de la serenidad y equilibrio producidos por la mansedumbre, están "la humildad, la fortaleza y la robustez," que han de constituirse en lo salesiano como una fuerza que, de sí misma y por consenso de un mundo que no teme colaborar con Don Bosco, les convierte en artífices de la no violencia activa.

San Juan Bosco no acepta la humillación, el pesimismo o el apocamiento entre los suyos. Su exquisita sencillez, le ubica en esa línea de la humildad, que "es andar en verdad". Mientras crece su obra de modo asustantemente imponente, decrece en su intimidad la importancia de lo conseguido frente a las exigencias de 
lo soñado. $Y$ en el sueño, que no es un sueño, quien lo promueve lo exige más. Dios no se cansa de hacerle soñar y realizar lo soñado, confiriéndole una fortaleza soberana, que la logra desde la integración comunitaria hasta la fidelidad en lo grande y en lo mínimo de cada uno de sus seguidores; mansedumbre, humildad y fortaleza hacen cada día más robusta la presencia salesiana en el mundo, de lo que son testigos la humanidad presente y la Iglesia de hoy.

Esa robustez impresiona inmensamente a la humanidad debilitada por la constancia de tanta violencia demoledora. Sin embargo, la sencillez filial del soñador nos invita a todos, especialmente a la juventud, a quienes la cuidan y forman ya los que no nos resignamos a envejecer y quisiéramos soñar más, a oír unas palabras que alguien compuso magistralmente, pensando en la mansedumbre del Juan Bosco de todo el universo:

"Mansos son los que saben alcanzar la victoria sin necesidad de violencias físicas. Saben que su causa y su tarea seguirán adelante a pesar de la violencia de todos los que se opongan, porque confían en Dios, que lleva adelante la historia. Son los que son fieles a su proyecto de vida sin claudicaciones, sin triunfalismos y sin pesimismos, porque experimentan la fuerza de Jesús. Son los que buscan la justicia para todos -también para sí mismos-, serenamente, pero sin dar jamás un paso atrás. Y por ello nunca colaboran con la injusticia. Son los que no conocen el miedo cuando se trata de un asunto de hermanos. Son los que optan por el mundo como Dios quiere y saben que no pueden ceder a ningún precio. Y así, entre los seguidores de Jesús, la mansedumbre y la fortaleza se hacen una sola cosa".

"Mansos son los tenaces, los pacientes, los que saben aguantar, los que saben sufrir, los que no ceden, a los que se puede romper pero no doblar, los que saben esperar y creer en tinieblas, los que han visto la luz. Son los que se lo juegan todo a la causa de Dios, que es la causa de la libertad, la justicia, la paz, el amor... que es la causa del pueblo. Y por ello, se unen a los débiles de este mundo y se enfrentan con el triple poder -político, económico y religioso- para defender su causa, que es la causa del Dios de Jesús. Son los que dan a los demás aun lo propio, los que hacen iguales y van por la vida creando un espacio de libertad". 
En un momento de clímax de violencia reactiva, que esconde en su desahogo carnicero, toda la injusticia que le victima y le hace victimario, el universo busca la mansedumbre creadora de personalidades como Juan Bosco Occhiena, el soñador que construyó el mundo salesiano y lo mantiene a ese mundo, a su sentido formador de juventudes, a su carismática vocación catequética y misionera, el mismo universo violento le grita exigiéndole esfuerzo para recuperar la mansedumbre, desde la cual el Soñador levantó toda su obra.

Por eso, de modo muy especial, la misma juventud, empujada a la delirante exhibición de las grandes impresiones técnicas, sujeta a la fascinación de las mil posibilidades de violento cambio y alteración de todos los órdenes, grita también con ansiedad, que todavía no adolece de alteración mental o cordial: "Universidad Politécnica Salesiana, matricula en todas tus aulas y ambientes a la necesitada mansedumbre de Don Bosco".

Jamás podrá decirse que no hay una relación muy lógica entre técnica y mansedumbre.

En la maravillosa hora serena de la plenitud creadora, cuando la urdimbre delicadísima de la vida funcionaba en la perfección original, el gran técnico de la vida comentó su obra, con extraordinaria simplicidad: "Todo está bien hecho". La vida, el pensamiento -"un solo pensamiento del hombre vale más que todo el universo"- , el complejo universo, el amor: todo está bien hecho. La extraordinaria técnica creadora conciliada serenamente con la inmensa vitalidad de los seres, funcionó con la más exacta serenidad y precisión. Después de tantos siglos y culturas, acaso destructores, es hora ya de que nuestras universidades y especialmente las politécnicas, se comprometan con la vida, educando a los vivientes en la creadora mansedumbre. Bauticen y confirmen los politécnicos a la "armonía preestablecida" del filósofo ateo, con el agua pura y la unción del óleo -simplicidad y ternura, fortaleza y humildad- quitándole su fanático determinismo, para purificarlo con la alegría creyente que es limpia y que se enraíza en la profundidad del ser, transformando lo técnico en lo más sencillo, limpio, puro y creador. 